\section{Navigating adaptive challenges in quality improvement}

\section{Peter J Pronovost}

EDITOR'S Many quality improvement CHOICE (QI) projects often fail to achieve their goals. Some fail for technical reasons, such as invalid measures, inattention to key contextual factors that determine the intervention's effectiveness, or not pilot testing the effort to identify and remove implementation barriers. But, an even larger number of projects fail because of adaptive challenges. 'Adaptive challenges can only be addressed through changes in people's priorities, beliefs, habits, and loyalties.' ${ }^{2}$ A challenge for leaders is engaging people in deciding the change is needed, while also accepting that there may be things people want to preserve. For example, convincing physicians to include nurses during patient rounds, but letting them work out the logistics. Technical challenges are issues for which there is knowledge to implement a solution. For example, prescribing a $\beta$ blocker to treat patients following an acute myocardial infarction, or installing computers outside patient rooms to quickly access electronic medical records. A common mistake is to treat an adaptive problem as a technical one. QI work has to address both technical and adaptive issues. The science must be robust yet it must address values, beliefs, and attributes of the group involved in the work.

There is clearly a science to QI. Strategies to implement interventions or changes require sound evidence, or at the very least

Correspondence to Dr Peter J Pronovost, The Johns Hopkins University, 1909 Thames Street, 2nd floor, Baltimore, MD 21231, USA;

ppronovo@jhmi.edu consensus among opinion leaders, supporting their effectiveness, ${ }^{3}$ and a methodology to apply the QI work such as translating evidence into practice. ${ }^{4}$ While careful attention to the technical and methodological work is important, equally important is the engagement of health professionals and others affected by the QI project. There is local context and culture to contend with, and also psychological, social and political dynamics of staff and managers, and the organisation's history and resources. One thing is certain, health professionals want to help rather than harm patients. If they do not engage in a project, they have a justified or perceived reason. While there may be some science to the adaptive work, right now it is mostly an art. In this essay I offer some metaphors and ideas, based on leadership theories ${ }^{5} 6$ and my experiences that could help local QI leaders navigate adaptive challenges and successfully implement QI efforts (table 1).

\section{BE UNWAVERING IN YOUR GOAL AND INVITE EVERYONE TO HELP YOU REACH IT}

While a teenager, I went camping with 24 other boys. We were sitting around the campfire, deciding which mountain we would attempt to climb the next morning. The camp counsellors broke us into three groups of eight boys, each group had a counsellor. The first counsellor pointed to a peak and said to his group, "That's the hill we're going to climb." $\mathrm{He}$ then described in tedious detail how the boys would climb it. There was little passion and many boys fell asleep during the boring recount. The second very laid-back counsellor approached his group and said, "There are a lot of great peaks here, I don't care which one we climb, you guys decide which one and how we get there." The boys argued among themselves, more passionate about disagreeing, indifferent about succeeding in their journey. The third counsellor came up to my group and said, "You see that hill over there, that peak has the most amazing view from the top. Now, I'm not sure we're going to get there. It's going to be challenging, and we have to collaborate like we never have before. But if we succeed, is it an amazing view." That counsellor had a bunch of revved up boys, ready to meet any challenge, passionate about the work and working together to achieve a common goal. I not only climbed a great peak that morning, I also learned an important leadership lesson. ${ }^{6}$

Leaders of QI activities are too often like the first two counsellors, either micromanaging and dictating how to achieve the work, or lacking courage, commitment, and accountability for the goals. Leaders should emulate the third counsellor, unwavering in the hill they climb and confident they will reach the top, yet humble enough to recognise that they need the wisdom, skill, and passion of the group to achieve their goal.

Among the many hospitals virtually eliminating bloodstream infections, I found hospital leaders who were unwavering in their goal to reduce these infections and confident they would succeed, and humble enough to ask everyone to help them get there. ${ }^{7}$ One ICU manager told me that she "handed her staff the Johns Hopkins checklist and daily goals form and told them to use it." I said, "I bet that did not go very well." She admitted "it did not." I suggested she motivate them by saying, "Our infection rates are high and you told me 
Table 1 Recommendations to approach adaptive challenges

\begin{tabular}{|c|c|c|}
\hline Recommendation & Explanation & Practical example \\
\hline $\begin{array}{l}\text { Be unwavering in your } \\
\text { goal and invite everyone } \\
\text { to help you reach it. }\end{array}$ & $\begin{array}{l}\text { Choose a goal you are confident can } \\
\text { be achieved and focus on reaching } \\
\text { this goal. Recognise that you cannot } \\
\text { reach this goal alone-you need the } \\
\text { wisdom, skill, and passion of others } \\
\text { to help achieve the goal. }\end{array}$ & $\begin{array}{l}\text { If some clinicians resist efforts to reduce } \\
\text { CLABSI, clarify that your goal is to reduce } \\
\text { infections, it has been done by others. } \\
\text { Yet, be sure to enlist the help of others, } \\
\text { such as ICU clinicians, infection } \\
\text { prevention experts, quality improvement } \\
\text { staff, and senior hospital leaders. }\end{array}$ \\
\hline $\begin{array}{l}\text { Surface the real and } \\
\text { perceived losses. }\end{array}$ & $\begin{array}{l}\text { People resist change because they fear } \\
\text { a real, but more often a perceived, loss. }\end{array}$ & $\begin{array}{l}\text { Some junior doctors and nurses resisted } \\
\text { change because they feared looking } \\
\text { incompetent in front of others. Senior } \\
\text { staff may fear perceived loss of } \\
\text { control or autonomy. }\end{array}$ \\
\hline $\begin{array}{l}\text { Communicate the need } \\
\text { for change. }\end{array}$ & $\begin{array}{l}\text { Clearly explain the need for change } \\
\text { so staff understand why instead of } \\
\text { guessing motives or resisting } \\
\text { the change. }\end{array}$ & $\begin{array}{l}\text { To engage staff in the effort to reduce } \\
\text { CLABSI, stories were told of patients } \\
\text { harmed from these infections; staff were } \\
\text { given data of their current infection } \\
\text { rates, and estimates of the number } \\
\text { of people predicted to die from those } \\
\text { infections. }\end{array}$ \\
\hline $\begin{array}{l}\text { Tune into what's in it } \\
\text { for me. }\end{array}$ & $\begin{array}{l}\text { Identify what staff care about, then } \\
\text { maximise the perceived benefits } \\
\text { and minimise the losses. }\end{array}$ & $\begin{array}{l}\text { When interdisciplinary rounds were first } \\
\text { implemented, some doctors feared it would } \\
\text { take too long. So, the number of pages } \\
\text { per day was estimated. When } \\
\text { the number of pages was shown to drop } \\
\text { significantly with rounds, the doctors } \\
\text { pushed to do this in other areas of } \\
\text { the hospital. }\end{array}$ \\
\hline $\begin{array}{l}\text { Seek to understand } \\
\text { rather than judge. }\end{array}$ & $\begin{array}{l}\text { Talk to dissenters; it is most likely } \\
\text { a barrier or concern causing them } \\
\text { to resist. }\end{array}$ & $\begin{array}{l}\text { A physician who was resisting a QI } \\
\text { intervention was labelled by administration } \\
\text { and QI leaders as obstructive, stating "he } \\
\text { will just need to tow the line". When I spoke } \\
\text { with him, he noted a previously unidentified } \\
\text { risk from the intervention. When steps were } \\
\text { taken to minimise this risk, he became a } \\
\text { local champion. }\end{array}$ \\
\hline $\begin{array}{l}\text { Monitor the organisational } \\
\text { pressure. }\end{array}$ & $\begin{array}{l}\text { Assess the ability to take on initiatives, } \\
\text { monitor the burden on you, staff and } \\
\text { the organization, and adjust workloads } \\
\text { accordingly. }\end{array}$ & $\begin{array}{l}\text { A hospital was in the middle of implementing } \\
\text { a new computer system, and being pressured } \\
\text { to implement QI programs required by } \\
\text { regulators. When I talked to staff about } \\
\text { implementing a new QI effort, it became } \\
\text { clear that their workload was too high and } \\
\text { the project would have to wait. }\end{array}$ \\
\hline
\end{tabular}

CLABSI, central line associated blood stream infection; ICU, intensive care unit; QI, quality improvement.

our communication could improve. Do you want to try to improve both? Here are some tools that have helped others. Let's use them to start the discussion and make them fit our culture, make them even better."

\section{SURFACE THE REAL AND PERCEIVED LOSSES}

Many leaders say that their employees, especially physicians, resist change; it's simply human nature. Still, something deeper is driving their resistance. I believe the more accurate driver of resistance is an individual's fear of loss that has a real and, often, a much larger perceived component. If communication is poor or occurs infrequently, if staff do not understand why they are being asked to change, then the perceived loss grows exponentially, like a cancer. ${ }^{5}$
I saw, firsthand, how perceived losses can derail a QI program when my research team and I were trying to persuade physicians to implement our program to reduce central lineassociated bloodstream infections. I was presenting before 300 clinicians from 40 hospitals, trying to convince them to implement this program. A surgeon was standing in the back of the room. About $2 \mathrm{~min}$ into my discussion he blurted out, "This stuff 
is a bunch of crap, there's no evidence to support it." The room went silent; the host turned white. Recognising this was an adaptive challenge, I knew we needed to have a conversation. I said, "Help me understand what you're resisting and why." The surgeon said, "There's no evidence supporting a full barrier drape over a three-quarter barrier drape. Why are you making us do these silly things?" I sensed the physician felt a loss of control and autonomy; non-physicians were recommending practices he did not feel were supported by evidence. "You are right," I replied. "There is limited evidence for full versus threequarter draping. We do know, however, that smaller drapes are less effective than larger ones and when full barrier precautions were used as a package, infections fell. When we used full drapes in Michigan, ${ }^{8}$ we virtually eliminated infections. Are there full barrier drapes in your central-line kits?" "Yes," he said; "the hospital made us put them in." I replied, "So the burden to you of using a full versus three-quarter drape is merely flipping the sheet one extra time; a flip that likely takes a few seconds. We've spent more time right now talking about this, than it would take you in a years-worth of flipping. I suspect there may be some other barrier that is bothering you. The drape is merely symbolic for another issue; can you help me understand what that might be?" He looked stunned, paused, and said, "Well, I just wanted you to admit that there really isn't hard evidence for use of the full barrier drape. But now that you explained it, I'm happy to use it." That surgeon went from standing alone to joining his team and becoming one of the champions of this work.

The leader's job in addressing the adaptive challenges is to surface the real and perceived losses. The real losses (perhaps time or autonomy), generally pale when compared with the perceived losses (perhaps feeling a loss of control, decreased power, or increased workload). QI leaders must talk with involved staff and help them discern the real from the perceived losses. Unfortunately, many interdisciplinary QI projects lack a forum or containing vessel in which to have these conversations. The leader should create one.

\section{COMMUNICATE THE NEED FOR CHANGE}

When my son was in third grade, he came home from school and he said, "Daddy, I'm afraid to go in the bathroom, there's monsters in there." Concerned, I called the teacher and asked what was going on. The teacher said, "We installed automatic flush toilets, but nobody told the children what we were doing or why." No wonder Ethan thought there were monsters in the bathroom!

How many times do we implement change programs without explaining our goal, what we are doing, and why it is necessary? When we are covert and do not explain the need for change, an individual's resistance grows and they equate silence with ulterior motives that likely mean a loss for them. The forum I mentioned earlier that leaders should create would be like a mixing bowl, in which all stakeholders could assemble in a safe place to discuss what is changing and why, what are the real and perceived risks and barriers to the change, and how the change will impact them. Such a safe environment would allow everyone to speak freely without repercussions and to be heard when alternative suggestions are made to the proposed plan. An adaptive leader will seek out and listen to the wisdom of the stakeholders.

\section{TUNE INTO WIIFM}

To facilitate adaptive change, QI leaders also need to tune into WIIFM (What's in it for me?). Aside from the fact that most health professionals hold the patient's health first, everyone wants to maximise their interests and get something from the change effort. The QI leader needs to identify what staff care about, then maximise the perceived benefits and minimise the losses. With physicians, WIIFM is often their time. If the proposed changes take longer than current practice, physicians will resist the change and how the change will be made unless the benefit is visible, important, and consistent with professional norms. When leading QI projects, I am fully transparent about the time commitment.

To reduce risks when implementing QI programs, staff are asked to commit to a short pilot test; to try it for a day, for one physician, or for one patient. Generally a measure of time is also included in the project, a measure that is meaningful to clinicians, such as pages per day, or minutes spent making rounds. For example, when piloting the daily goals checklist, ${ }^{9}$ which involved rounding with nurses on a medicalsurgical floor to establish a clear plan of care for each patient, the surgeons were initially resistant. They thought making rounds every day with the nurses would "take too much time". I said that "I doubted it would be time lost because they are paged so often now to clarify questions that could be more efficiently clarified on rounds." The surgeons clearly recognised that they were paged often, but did not know how often. So, the unit clerk was asked to monitor and log every page over a period of time to see what happened. Pages went from 64 a day before daily goals' use to two afterwards. Not only did the doctors become champions of this work, they helped spread it to other units, and refused to round without the nurses.

\section{SEEK TO UNDERSTAND RATHER THAN} JUDGE

When clinicians resist a QI activity, they have a justified or perceived 
reason. Rather than judge their intentions, find out why they are resisting; value rather than vilify the dissenter. $^{10}$ It is more effective to assume that a barrier is likely the root of resistance. The QI leader's job is to surface and mitigate those barriers. Rather than bullying or avoiding the dissenter, embrace them, talk to them. Listen and understand why they are resisting. In most cases, there will be some truth to their resistance. The intervention may pose unrecognised risks or burdens.

Moreover, it is easy to forget that harm is usually the result of system failures that most often position clinicians to make mistakes. ${ }^{11}$ Yet, when we step back from the sharp end where clinicians interface with patients, we still blame and judge others. This is destructive for $\mathrm{QI}$ and deters progress.

\section{MONITOR THE ORGANISATIONAL PRESSURE}

The healthcare industry is in the midst of unprecedented change. Healthcare organisations are inundated with implementing new information systems and technologies, and with meeting regulations from The Joint Commission and other external agencies. Many healthcare organisations are under significant financial pressures, asking staff to do more work with fewer resources. Staff feel overwhelmed and near the boiling point. No wonder staff resist new QI projects. The QI leader should view the organisation as a pressure cooker and check the gauge before throwing in another initiative that could increase the pressure and cause an explosion. ${ }^{5}$

The QI leader must monitor the pressure, turning the heat up when it is cooking too slow, turning it down when the pressure is too high. Pressure can occur within yourself, your team, and your organisation. The QI leader needs a deep understanding of all three levels. If accomplished, he/she will know when to push harder and when to back off.

The technical and adaptive work of QI is equally important, but overcoming the complex adaptive challenges will determine whether your intervention is adopted and implemented. ${ }^{12}$ A national effort to eliminate central line-associated bloodstream infections implements a culture-based program first to tackle adaptive challenges before the intervention to prevent infections. ${ }^{13}$ The concepts described in this essay are based on the leadership theories of Heifetz and others, and on my trying them in QI efforts, simplifying them, and developing metaphors to share them. They are practical, time tested, and seem to be effective in helping to overcome adaptive challenges.

Acknowledgements The author wishes to thank Christine G Holzmueller, BLA (Honours) for editing this manuscript.

Competing interests Dr Pronovost reports the following potential competing interests: grant or contract support from the Agency for Healthcare Research and Quality, the National Patient Safety Agency (UK), the Robert Wood Johnson Foundation, and The Commonwealth Fund for research related to measuring and improving patient safety; honoraria from various hospitals and health systems and the Leigh speakers Bureau to speak on quality and safety; consultancy with the
Association for Professionals in Infection Control and Epidemiology, Inc.; and book royalties for authoring Safe Patients, Smart Hospitals: How One Doctor's Checklist Can Help Us Change Health Care from the Inside Out.

Provenance and peer review Not commissioned; externally peer reviewed.

Published Online First 21 May 2011

BMJ Qual Saf 2011;20:560-563.

doi:10.1136/bmjqs-2011-000026

\section{REFERENCES}

1. Heifetz R, Grashow A, Linsky M. The theory behind the practice. The practice of adaptive leadership. Boston, MA: Harvard Business Press, 2009:19.

2. Heifetz RA. Leadership without easy answers. Cambridge, MA: The Belknap Press of Harvard Press, 1994

3. Grol R. Personal paper. Beliefs and evidence in changing clinical practice. BMJ 1997;315:418-21.

4. Pronovost PJ, Berenholtz SM, Needham DM. Translating evidence into practice: a model for large scale knowledge translation. BMJ 2008;337:963-5.

5. Heifetz M, Halle S. Leading change, overcoming chaos-making change succeed in your organization. Hosp Mater Manage Q 1996;18:17-27.

6. Hackman JR. Leading teams: setting the stage for great performances. Boston, MA: Harvard Business School Press, 2002.

7. Pronovost $\mathrm{P}$, Needham $\mathrm{D}$, Berenholtz $\mathrm{S}$, et al. An intervention to decrease catheter-related bloodstream infections in the ICU. N Engl J Med 2006;355:2725-32.

8. Pronovost PJ, Goeschel CA, Colantuoni E et al. Sustaining reductions in catheter related bloodstream infections in Michigan intensive care units: observational study. BMJ 2010;340:c309.

9. Holzmueller CG, Timmel J, Kent PS, et al. Implementing a team-based daily goals sheet in a non-ICU setting. Jt Comm J Qual Patient Saf 2009;35:384-8.

10. Jain SH, Cassel CK. Societal perceptions of physicians: knights, knaves, or pawns? JAMA 2010;304:1009-10.

11. Reason JT. Human error. New York: Cambridge University Press, 1990.

12. Pronovost PJ, Marsteller JA, Goeschel CA. Preventing bloodstream infections: a measurable national success story in quality improvement. Health Aff (Millwood) 2011;30:628-34

13. Dixon-Woods M, Bosk CL, Aveling E, et al Explaining Michigan: developing an ex post theory of a quality improvement program. Milbank Q 2011. in press. 